\title{
EDITORIAL
}

\section{Positive thinking}

\author{
The importance of SoapBox Science and other initiatives that increase the visibility of \\ female role models in science should not be underestimated.
}

The South Bank in London, UK, runs alongside the River Thames between Westminster Bridge and London Bridge. From the London Eye and the Southbank Centre in the West, past Tate Modern to Sir Francis Drake's The Golden Hinde in the East, the area is immensely popular with both Londoners and tourists alike and has been host to performers of all ilks for centuries; indeed, since 1997 it has been home to a reconstruction of Shakespeare's Globe, which was built just a few hundred metres from the site of the original Globe Theatre that opened at the beginning of the seventeenth century.

On 5 July 2013, however, the area of the South Bank adjacent to Gabriel's Wharf was home to some perhaps unexpected performers: scientists. Twelve female scientists, to be precise, participating in a science communication initiative known as Soapbox Science. This event, which is supported by the L'Oreal UNESCO For Women In Science Scheme and the Zoological Society for London and is led by Seirian Sumner and Nathalie Pettorelli, is now in its third year and aims to increase the visibility of female scientists working at the forefront of their disciplines in the United Kingdom. Over a 3-hour period, the scientists each don their lab coats and use their soapbox as a platform to talk directly to passersby about their passion for their work and its broader implications, and the fun they have had in pursuit of their scientific dreams. The hope is that the event itself and any subsequent press and social media coverage will inspire people to think about science in general. More specifically, it will hopefully signal to young girls that there are many top female scientists who are all passionately interested in the further pursuit of their research and in inspiring the next generation.

For readers of Nature Reviews Microbiology, this year's event was of particular interest, as two of the 12 scientists selected from the more than 70 who applied were prominent UK microbiologists: Professor Hilary LappinScott, of the University of Swansea, and Professor Laura Piddock, of the University of Birmingham, whose soapbox stints were additionally sponsored by the Society for General Microbiology (SGM) and the British Society for Antimicrobial Chemotherapy (BSAC), respectively. Both women are highly regarded researchers in their respective fields of biofilms and antimicrobial resistance, and they are also excellent role models for other women in science and champions for increased public engagement. Professor Lappin-Scott is a past president of the SGM - only the second female president in the society's history - and was a key figure behind the creation of the SGM's new Equality and Diversity Working Group, which she currently chairs. As the BSAC Chair of Public Engagement, Professor Piddock is the driving force behind the highly successful Antibiotic Action campaign, which aims to highlight the problems associated with antibiotic resistance not only to science and medical professionals but also to the general public.

July also heralded another Wikipedia 'edit-a-thon', in which there is a concerted drive to redress the gender balance on Wikipedia by adding new entries for inspirational female scientists, past and present, who are not represented, as well as expanding the information available on those individuals for whom the existing entries are limited. The first such event was held on 19 October 2012 at the UK Royal Society to mark Ada Lovelace Day, and the latest was held on 25 July 2013 at the UK Medical Research Council (MRC) to mark what would have been Rosalind Franklin's ninety-third birthday. The aim, again, is to increase the visibility of positive role models for young women who may be considering a career in science. As part of their centenary celebrations, the MRC plans to hold another five edita-thons before the end of the year at various locations around the United Kingdom.

The issue of the so-called leaky pipeline for women studying and working in STEM (science, technology and medicine) subjects is enormously complex, and tackling it is a huge challenge. Any initiatives that increase the number of positive role models for young girls are thus very welcome. It is interesting to note, therefore, that in the United States, the latest round of presidential nominations to fill key administrative posts includes microbiologist Dr Jo Handelsman of Yale University, New Haven, Connecticut, as the nominee for Associate Director for Science in the Office of Science and Technology Policy, and astrophysicist Dr France Anne Córdova as the nominee for Director of the National Science Foundation, following in Rita Colwell's footsteps. Having women in such prominent positions is a small but important step in the right direction. 